\title{
KARAKTERISTIK KELUARGA TERHADAP KEJADIAN STUNTING PADA ANAK SEKOLAH DASAR DI KECAMATAN NANGGALO KOTA PADANG
}

\author{
Oktariyani Dasril, Annita \\ (Program Studi Kesehatan Masyarakat Stikes Syedza Saintika)
}

\begin{abstract}
Stunting is a state of the body that is very short beyond the -2 SD deficit below the median (WHO, 2013). Report of the Padang City Health Office in 2017, where the incidence of stunting at the Lapai Public Health Center was $17.7 \%$. The purpose of this study is to look at the family characteristics of stunting in elementary school children in Nanggalo District, Padang City. This type of analytic research with cross sectional design. The population of all first grade students in five public and private elementary schools is 124 people. While sampling uses a total sampling technique. Data collection on students was measured height (TB), the mother was interviewed about family characteristics related to nutritional status (level of education, economic status and parenting in the family) using a questionnaire guide. The study was conducted in May - September 2019. Data were analyzed univariately and bivariately using computerization. The results showed that $25 \%$ of respondents stunted, $19.4 \%$ had low maternal education, $24.2 \%$ had low family economic status and $48.4 \%$ of children had poor parenting. There is a relationship between family characteristics, namely the level of education $(p=0,000)$, economic status $(p=0,000)$ and parenting $(p=0,007)$ with the incidence of stunting in Elementary School Children in Nanggalo District, Padang City. It is recommended that parents and health workers to improve nutritional status and reduce the incidence of stunting in children.
\end{abstract}

Keywords: characteristics family; stunting; chils elementary school

\section{PENDAHULUAN}

Pembangunan nasional mempunyai tujuan utama yaitu meningkatkan kualitas sumber daya manusia (SDM) yang dilakukan secara berkelanjutan. Upaya peningkatan kualitas SDM dimulai dengan pemenuhan kebutuhan dasar manusia dengan perhatian utama pada proses tumbuh kembang anak ${ }^{1}$. Anak sekolah merupakan salah satu aset sumber daya manusia dimasa depan yang perlu mendapat perhatian khusus. Adanya peningkatan dan perbaikan kualitas hidup anak merupakan salah satu upaya yang penting bagi kelangsungan hidup suatu bangsa. Kualitas hidup anak dapat dilihat kesehatannya melalui keadaan status gizi yang baik dan merupakan salah satu indikator pembangunan. Status gizi anak merupakan satu dari delapan tujuan yang akan dicapai dalam Millenium Development Goals (MDGs) 2015, dampak dari status gizi rendah yaitu pada usia sekolah akan mengakibatkananak menjadi lemah, cepat lelah dan mudah sakit oleh karena itu anak-anak seringkali absen serta mengalami kesulitan dalam mengikuti dan memehami pelajaran ${ }^{2}$.

Perubahan ukuran fisik penduduk merupakan salah satu indikator keberhasilan upaya peningkatan kualitas sumber daya manusia. Salah satu cara untuk mengetahui perkembangan pertumbuhan fisik penduduk adalah melalui pengukuran Tinggi Badan Anak 
Baru Masuk Sekolah (TBABS) ${ }^{1}$. Kejadian stunting pada anak usia sekolah dasar merupakan manifestasi dari stunting pada waktu balita, karena tidak ada perbaikan tumbuh kejar (catch up growth) asupan zat gizi makro dan mikro yang tidak sesuai kebutuhan dalam jangka lama, disertai penyakit infeksi. Laju pertumbuhan baik laki-laki maupun perempuan melambat antara usia 6-9 tahun $^{3}$

Berdasarkan Riset Kesehatan Dasar (RISKESDAS) tahun 2013 diketahui bahwa prevalensi kejadian stunting secara nasional adalah 37,2\%, yang terdiri dari $18,0 \%$ sangat pendek dan 19,2\% pendek. Data nasional, dari 33 provinsi di Indonesia terdapat 20 provinsi dengan prevalensi stunting diatas rata-rata prevalensi nasional ${ }^{4}$. Data Dinas Kesehatan Sumatera Barat tahun 2015, prevalensi stunting di Kota Padang sebesar 15\%. Prevalensi tertinggi berada di Kabupaten Solok dan prevalensi terendah di Kota Solok, sedangkan Kota Padang berada pada urutan ke-13 dari 19 Kabupaten/Kota yang ada di Sumatera Barat ${ }^{5}$. Riset Kesehatan Dasar 2018 mencatat prevalensi stunting nasional mencapai 30,8 persen, menurun dari tahun 2013 (37,2\%) dan 2010 (35,6\%) dan Hasil prevalesi pendek menurut Riskesdas (2018) menunjukkan semua provinsi di Indonesia sudah dalam kondisi baik kesehatan masyarakat. Angka tersebut sudah dikategorikan rendah karena sudah berada di dibawah target MDG"s yaitu $32 \%{ }^{6}$.

Hasil penelitian yang dilakukan ${ }^{2}$ diketahui bahwa prevalensi stunting pada anak baru masuk sekolah memiliki hubungan yang bermakna dengan pendidikan ibu dan tingkat ekonomi keluarga. Kebanyaan anak yang mudah menderita Stunting berasal dari keluarga besar dengan daya beli rendah, kondisi rumah buruk, tidak punya penyediaan air bersih yang memenuhi persyaratan kesehatan, pendidikan orang tuanya yang rendah dan sikap serta kebiasaan yang tidak menguntungkan. Karena itu faktor edukasi dan perbaikan ekonomi sangat berperan dalam pencegahan dan penanggulangan Stunting ${ }^{2}$. Dalam sebuah Hasil penelitian yang dilakukan oleh Aramico tahun 2013 tentang Hubungan sosial ekonomi, pola asuh, pola makan dengan stunting pada siswa sekolah dasar di Kecamatan Lut Tawar, Kabupaten Aceh Tengah ditemukan bahwa adanya hubungan antara sosial ekonomi, pola asuh, dan pola makan dengan stunting ${ }^{7}$.

Konsumsi makanan berpengaruh terhadap status gizi seseorang. Status gizi baik atau gizi optimal terjadi bila tubuh memperoleh cukup zat-zat gizi yang digunakan secara efisien, sehingga memungkinkan pertumbuhan fisik, perkembangan otak, kemampuan kerja dan kesehatan secara umum pada tingkat setinggi mungkin ${ }^{8}$. Menurut hasil penelitian yang dilakukan oleh Firdaus (2016) tentang analisis pola asuh orang tua dengan status gizi Anak prasekolah di RT 01 RW 01 desa Manunggal bangkalan madura menunjukkan bahwa Adanya hubungan pola asuh orang tua dengan status gizi anak pra sekolah ${ }^{9}$. 
Berdasarkan permasalahan diatas menarik penulis untuk melakukan penelitian yang bertujuan mengetahui hubungan karakteristik keluarga terhadap kejadian stunting pada anak sekolah dasar di Kecamatan Nanggalo Kota Padang.

\section{METODE PENELITIAN}

Penelitian ini menggunakan desain penelitian observasional analitik dengan pendekatan cross sectional study, yaitu penelitian dalam rangka mempelajari karakteristik keluarga terhadap kejadian stunting pada anak sekolah dasar di Kecamatan Nanggalo Kota Padang. Variabel dependen dalam penelitian ini adalah kejadian stunting pada anak sekolah dasar, dan variabel independennya adalah karakteristik keluarga yang terdiri dari tingkat pendidikan, status ekonomi dan pola asuh makan anak. Penelitian ini dilakukan di lima sekolah dasar negri dan swasta yang memiliki angka kejadian stunting tertinggi di Kecamatan Nanggalo Kota Padang yakni; SDN 01 Kampung Olo, SDN 02 Kampung Olo, SDN 03 Kampung Olo, SDN 18 Kampung Laopai dan SD Sabbihisma

Pengumpulan data primer terhadap murid SD dilakukan pengukuran tinggi badan (TB) menggunakan microtoice dengan ketelitian $0,1 \mathrm{~cm}$ dan wawancara tentang karakteristik keluarga yang berhubungan dengan status gizi (tingkat pendidikan, status ekonomi, tingkat pengetahuan tentang gizi, status pekerjaan dan jumlah anggota keluarga) dengan menggunakan panduan kuesioner. Status gizi stunting ditegakkan berdasarkan kriteria tinggi badan apabila berada $<-2$ SD.

\section{HASIL PENELITIAN}

\section{A. Kejadian Stunting}

Kejadian Stunting pada anak dapat dinilai dari status gizi anak dengan menggunakan indeks Tinggi Badan menurut Umur (TB/U). Gambaran kejadian stunting pada anak berdasarkan TB/U pada penelitian terdapat kurang dari separoh yaitu 31 responden (25\%) dengan kejadian stunting pada anak sekolah dasar di Kecamatan Nanggalo Kota Padang.

\section{B. Karakteristik Keluarga}

\section{Pendidikan Ibu}

Tingkat pendidikan ibu responden dilihat dari jenjang pendidikan dengan mendapatkan ijazah terakhir terdapat kurang dari separoh yaitu 31 responden $(19,4 \%)$ mempunyai pendidikan ibu rendah pada anak sekolah dasar di Kecamatan Nanggalo Kota Padang.

\section{Status Ekonomi Keluarga}

Hasil penelitian menunjukan bahwa dari 124 responden terdapat kurang dari separoh yaitu 30 responden (24,2\%) mempunyai status sosial ekonomi rendah pada anak sekolah dasar di Kecamatan Nanggalo Kota Padang. 


\section{Pola Asuh Makan}

Hasil penelitian menunjukan bahwa dari 124 responden terdapat kurang dari separoh yaitu 60 responden $(48,4 \%)$ mempunyai pola asuh makan yang tidak baik pada anak sekolah dasar di Kecamatan Nanggalo Kota Padang.

\section{Hubungan Pendidikan lbu dengan Kejadian Stunting}

Tabel 1. Hubungan Pendidikan Ibu dengan Kejadian Stunting

\begin{tabular}{lccccccc}
\hline \multirow{2}{*}{$\begin{array}{c}\text { Pendidikan } \\
\text { Ibu }\end{array}$} & \multicolumn{4}{c}{ Kejadian Stunting } & \multicolumn{2}{c}{ Total } & \multirow{2}{*}{ P-Value } \\
\cline { 2 - 6 } & $\mathbf{f}$ & $\%$ & $\mathbf{f}$ & $\%$ & $\mathbf{f}$ & $\%$ & \\
\hline Rendah & 16 & 66,7 & 8 & 33,3 & 24 & 100 & \\
Tinggi & 15 & 15 & 85 & 85 & 100 & 100 & 0,000 \\
$\quad$ Jumlah & 31 & 25 & 93 & 75 & 124 & 100 & \\
\hline
\end{tabular}

Berdasarkan tabel 1 diketahui bahwa dari 24 responden yang memiliki pendidikan ibu rendah terdapat 16 responden yang menderita stunting $(66,7 \%)$, sedangkan 8 responden tidak menderita stunting (33,3\%). Hasil uji statistik Chisquare menunjukan ada hubungan yang signifikan antara pendidikan ibu dengan kejadian stunting pada anak sekolah dasar di Kecamatan Nanggalo Kota Padang dengan $p=0,000$ ( $p$ value $<0,05$ ).

\section{Hubungan Status Ekonomi Keluarga dengan Kejadian Stunting}

Tabel 2. Hubungan Status Ekonomi Keluarga dengan Kejadian Stunting

\begin{tabular}{|c|c|c|c|c|c|c|c|}
\hline \multirow{3}{*}{$\begin{array}{l}\text { Status } \\
\text { Ekonomi }\end{array}$} & \multicolumn{4}{|c|}{ Kejadian Stunting } & \multirow{2}{*}{\multicolumn{2}{|c|}{ Total }} & \multirow{3}{*}{ P-Value } \\
\hline & \multicolumn{2}{|c|}{ lya } & \multicolumn{2}{|c|}{ Tidak } & & & \\
\hline & $f$ & $\%$ & $f$ & $\%$ & $f$ & $\%$ & \\
\hline Rendah & 28 & 93,2 & 2 & 6,7 & 30 & 100 & \multirow{3}{*}{0,000} \\
\hline Tinggi & 3 & 3,2 & 91 & 96,8 & 94 & 100 & \\
\hline Jumlah & 31 & 25 & 93 & 75 & 124 & 100 & \\
\hline
\end{tabular}

Berdasarkan tabel 2 diketahui bahwa dari 30 responden yang memiliki status ekonomi keluarga rendah terdapat 28 responden yang menderita stunting $(93,2 \%)$, sedangkan 2 responden tidak menderita stunting $(6,7 \%)$. Hasil uji statistik Chisquare menunjukan ada hubungan yang signifikan antara status ekonomi keluarga dengan kejadian stunting pada anak sekolah dasar di Kecamatan Nanggalo Kota Padang dengan $p=0,000$ ( $p$ value $<0,05$ ). 


\section{Hubungan Pola Asuh Makan dengan Kejadian Stunting}

Tabel 3. Hubungan Pola Asuh Makan dengan Kejadian Stunting

\begin{tabular}{|c|c|c|c|c|c|c|c|}
\hline \multirow{3}{*}{$\begin{array}{c}\text { Pola Asuh } \\
\text { Makan }\end{array}$} & \multicolumn{4}{|c|}{ Kejadian Stunting } & \multirow{2}{*}{\multicolumn{2}{|c|}{ Total }} & \multirow{3}{*}{ P-Value } \\
\hline & \multicolumn{2}{|c|}{ lya } & \multicolumn{2}{|c|}{ Tidak } & & & \\
\hline & f & $\%$ & f & $\%$ & f & $\%$ & \\
\hline Tidak Baik & 8 & 13,3 & 52 & 86,7 & 60 & 100 & \\
\hline Baik & 23 & 35,9 & 41 & 64,1 & 64 & 100 & 0,007 \\
\hline Jumlah & 31 & 25 & 93 & 75 & 124 & 100 & \\
\hline
\end{tabular}

Berdasarkan tabel 3 diketahui bahwa bahwa dari 60 responden yang memiliki pola asuh makan tidak baik terdapat 8 responden yang menderita stunting $(13,3 \%)$, sedangkan 52 responden tidak menderita stunting (86,7\%). Hasil uji statistik Chisquare menunjukan ada hubungan yang signifikan antara pola asuh makan dengan kejadian stunting pada anak sekolah dasar di Kecamatan Nanggalo Kota Padang dengan $p=0,007$ ( $p$ value $<0,05)$.

\section{PEMBAHASAN}

\section{A. Kejadian Stunting}

Hasil penelitian ini sejalan dengan ${ }^{2}$ pada anak sekolah dasar di Kecamatan Lubuk Kilangan Kota Padang, hasil penelitian menunjukan hampir separoh responden (35\%) menderita kejadiaan stunting. Hasil penelitian ini juga sejalan dengan penelitian ${ }^{7}$ pada siswa sekolah dasar di di Kecamatan Lut Tawar Aceh Tengah yang mana kurang dari separoh responden $(30,1 \%)$ menderita stunting.

Stunting adalah keterlambatan/gangguan pertumbuhan rangka tubuh sehingga badan menjadi pendek, yang sering timbul karena kurangnya suplai makanan dan daya beli rendah. Seseorang dikatakan stunting apabila indeks TB/U $\leq 2$ SD ${ }^{1}$. Pengukuran tinggi badan pada responden dilakukan dengan mengginakan microtoise di kelasnya, setiap anak yang diukur terkadang lupa untuk membuka sepatu dan kaos kaki, sehingga dibutuhkan ketelitian peneliti pada saat melakukan pengukuran.

\section{B. Karakteristik Keluarga}

\section{Pendidikan Ibu}

Hasil penelitian ini sejalan dengan penelitian ${ }^{2}$ pada anak sekolah dasar di Kecamatan Lubuk Kilangan Kota Padang, hasil penelitian menunjukan kurang dari separoh responden dengan pendidikan ibu rendah (39\%). Namun hasil penelitian ini tidak sejalan dengan penelitian ${ }^{10}$ pada anak sekolah dasar negeri 014610 Sei 
Renggas Kecamatan Kisaran Barat Kabupaten Asahan yang menyatakan lebih dari separoh responden (56,2\%) dengan ibu berpendidikan rendah.

Orang tua yang mempunyai pendidikan yang tinggi maka mengolah informasi yang bermanfaat bagi dirinya dan keluarganya, yang berkaitan dengan cara mengasuh anak, menjaga kesehatan anak, pendidikan serata yang lainnya. Dalam hal konsumsi makanan juga demikian. Dengan ayah dan ibu yang berpendidikan yang tinggi, akan mampu mendidik anak-anaknya agar berperilaku makan dengan baik. Dengan pembiasaan makan yang baik, maka perilaku makan anak akan terbentuk dengan baik pula ${ }^{11}$

\section{Status Ekonomi Keluarga}

Hasil penelitian ini sejalan dengan penelitian yang dilakukan oleh ${ }^{12}$ di Pakistan tentang , hasil penelitian menyatakan kurang dari separoh responden (35\%) tinggal pada golongan pendapatan keluarga rendah. Hasil penelitian ini tidak sejalan dengan penelitian Lestari et al tentang faktor risiko stunting pada anak sekolah di Kabupaten Asahan tahun 2018, hasil penelitian menyatakan lebih dari separoh responden $(70,3 \%)$ yang mempunyai status ekonomi (pendapatan keluarga) kategori rendah.

Status ekonomi keluarga adalah kemampuan perekonomian suatu keluarga dalam memenuhi setiap kebutuhan hidup seluruh anggota keluarga. Tingkat sosial ekonomi terutama penghasilan sanat berpengaruh pada pemenuhan kebutuhan hidup seseorang dan keluarga, kemiskinan (sosial ekonomi rendah) merupakan keadaan yang mengarah pada kondisi kerja yang buruk, perumahan yang terlalu padat, lingkungan yang buruk serta malnutrisi (gizi buruk) karena kurangnya kemampuan untuk memenuhi kebutuhan hidup ${ }^{13}$

\section{Pola Asuh Makan}

Hasi penelitian ini sejalan dengan penelitian ${ }^{7}$ pada siswa sekolah dasar di Kabupaten Aceh Tengah, yang mana hasil penelitiannya menyatakan bahwa kurang dari seperoh responden dengan pola asuh makan yang kurang baik $(43,9 \%)$. Pola asuh makan orang tua kepada anak atau parental feeding adalah perilaku orang tua yang menunjukan bahwa mereka memberikan makan pada anak baik dengan pertimbangan atau tanpa pertimbangan ${ }^{14}$

Pola pengasuhan adalah kemampuan keluarga dan masyarakat untuk menyeiakan waktu, perhatian, dan dukungan terhadap anak agar dapat tumbuh kembang dengan optimis baik fisik, mental dan sosial. Pola asuh yang baik sangat mendukung tercapainya status gizi yang optimis, melalui perawatan yang menyeluruh dari orang tua terhadap tumbuh kembang anaknya. 


\section{Hubungan Pendidikan Ibu dengan Kejadian Stunting}

Hasil penelitian ini sejalan dengan Penelitian ini juga sejalan dengan penelitian yang dilakukan oleh ${ }^{15}$ di Nigeria yang mana anak dengan stunting lebih banyak terjadi pada ibu dengan pendidikan rendah dan terdapat hubungan pendidikan ibu dengan kejadian stunting pada anak sekolah dengan $p$ value 0,000 . Pendidikan ibu merupakan hal dasar bagi tercapainya gizi anak yang baik. Tingkat pendidikan ibu tersebut terkait dengan kemudahan ibu dalam menerima informasi tentang gizi dan kesehatan dari luar. Tingkat pendidikan merupakan salah satu faktor yang mempengaruhi dari perubahan perilaku seseorang. Ibu dengan tingkat pendidikan yang lebih tinggi akan lebih mudah menerima informasi dari luar, dibandingkan dengan ibu yang memiliki tingkat pendidikan lebih rendah ${ }^{16}$

Asumsi peneliti pada penelitian ini, pendidikan ibu mempengaruhi kelangsungan hidup anak secara langsung dengan meningkatkan keterampilannya dalam aneka ragam upaya perawatan kesehatan yang berkaitan dengan peningkatan gizi, peningkatan kesehatan dan pencegahan serta pengobatan penyakit. Tingkat pendidikan ibu sangat berpengaruh terhadap kualitas dan kuantitas makanan yang dikonsumsi keluarga karena ibu memegang peranan penting dalam pengelolaan rumah tangga

\section{Hubungan Status Ekonomi Keluarga dengan Kejadian Stunting}

Hasil penelitian ini sejalan dengan penelitian yang dilakukan Mushtaq et al (2018) di Pakistan yang menyatakan bahwa anak stunting banyak terdapat didaerah/ lingkungan yang berpenghasilan rendah dengan $p$ value 0,001 . Hasil penelitian ini juga sejalan dengan penelitian ${ }^{10}$ terdapat hubungan antara pendapatan keluarga dengan stunting pada anak SD Negeri 014610 Sei Renggas Kecamatan Kisaran Barat Kabupaten Asahan dengan $p$ value 0, 000.

Tingkat ekonomi seseorang berhubungan erat dengan berbagai masalah kesehatan. Orang dengan tingkat ekonomi rendah akan lebih berkonsentrasu terhadap pemenuhan kebutuhan dasar yang menunjang kehidupannya dan kehidupan keluarganya. ${ }^{16}$ Menurut asumsi peneliti kondisi perekonomian keluarga yang rendah pada responden yang ditemui memberikan perpengaruh terhadap satus gizi anggota keluarganya, terutama pada anak. Masalah gizi kurang yang terus berlanjut terutama pada anak sekolah yang masih dalam masa pertumbuhan nanti akan memberikan dampak negatif terhadap pertumbuhan fisik mereka (stunted).

\section{Hubungan Pola Asuh Makan dengan Kejadian Stunting}

Hasil penelitian ini sejalan dengan penelitian yang dilakukan ${ }^{7}$ analisis menunjukkan terdapat hubungan yang bermakna antara pola asuh makan dengan stunting pada anak sekolah dasar dengan $p$ value $=0,000$ ( $p$ value $<0,005$ ) yang 
mana pola asuh makan yang kurang baik banyak terjadi pada anak stunting. Stunting pada anak dipengaruhi oleh perilaku orang tua terutama dalam pola asuh anak. Orang tua terutama ibu memiliki peran penting untuk memberikan perawatan dan pengasuhan yang berkualitas sesuai dengan tahap perkembangan anak. Kebutuhan fisik biomedis (asuh) meliputi kebutuhan pangan dan gizi. Pola pengasuhan yang berkualitas mampu menekan dan mengurangi kasus stunting atau kekerdilan akibat kekurangan gizi pada anak-anak. ${ }^{8}$

Menurut hasil penelitian di Sekolah Dasar yang ada Di Kecamatan Nanggalo, Pola pengasuhan anak sangat mempengaruhi pertumbuhan dan perkembangan anak karena anak yang mendapat perhatian lebih baik secara fisik maupun emosional keadaan gizinya lebih baik dibandingkan dengan teman sebayanya yang kurang mendapat perhatian. (Data Primer Hasil Penelitian,2019).

\section{SIMPULAN DAN SARAN}

Berdasarkan hasil penelitian dapat ditarik kesimpulan bahwa; kejadian stunting pada anak sebanyak $25 \%$, tingkat pendidikan ibu yang rendah sebanyak $19,4 \%$, status ekonomi keluarga yang rendah $18,5 \%$, dan pola asuh makan yang tidak baik sebanyak $48,4 \%$. Serta adanya hubungan yang bermakna antara pendidikan ibu $(p=0,000)$, status ekonomi keluarga $(\mathrm{p}=0,000)$ dan pola asuh makan $(\mathrm{p}=0,000)$ terhadap kejadian stunting pada anak sekolah dasar di Kecamatan Nanggalo Kota Padang. Disarankan orang tua dan tenaga kesehatan untuk meningkatkan status gizi dan menurunkan angka kejadian stunting pada anak

\section{DAFTAR PUSTAKA}

1. Kementrian Kesehatan. Standar Antropometri Penilaian Status Gizi Anak. Standar Antropometri Penilai Status Gizi Anak. 2010:40.

2. Sulastri D. FAKTOR DETERMINAN KEJADIAN STUNTING PADA ANAK USIA SEKOLAH DI KECAMATAN LUBUK KILANGAN KOTA PADANG. Maj Kedokt Andalas. 2012. doi:10.22338/mka.v36.i1.p39-50.2012

3. Sulistiyoningsih. Gizi Untuk Kesehatan Ibu Dan Anak. Yogyakarta: Graha Ilmu; 2011.

4. Badan Penelitian dan Pengembangan Kesehatan. Riset Kesehatan Dasar 2013. Ris Kesehat Dasar 2013. 2013.

5. Dinas Kesehatan Provinsi. Profil Dinas Kesehatan Propinsi Sumatera Barat. Padang; 2015.

6. Riskesdas 2018. Riskesdas 2018. Kementrian Kesehat Republik Indones. 2018. doi:1 Desember 2013

7. Aramico B, Sudargo T, Susilo J. Hubungan sosial ekonomi, pola asuh, pola makan dengan stunting pada siswa sekolah dasar di Kecamatan Lut Tawar, Kabupaten Aceh 
Tengah. J Gizi dan Diet Indones (Indonesian J Nutr Diet. 2016. doi:10.21927/ijnd.2013.1(3).121-130

8. Soetjiningsih IGR. Tumbuh Kembang Anak. Jakarta: EGC; 2008.

9. Firdaus, Muafiif M. Analisis Pola Asuh Orang Tua Dengan Status Gizi Anak Prasekolah Di Rt 01 Rw 01 Desa Manunggal Bangkalan Madura. J Heal Sci. 2016.

10. Lestari W, Rezeki SHI, Siregar DM, Manggabarani S. Faktor Yang Berhubungan dengan Kejadian Stunting Pada Anak Sekolah Dasar Negeri 014610 Sei Renggas Kecamatan Kisaran Barat Kabupaten Asahan. J Dunia Gizi. 2018. doi:10.33085/jdg.v1i1.2926

11. Putri RM, H WR, Maemunah N. Kaitan Pendidikan,Pekerjaan Orang Tua Dengan Status Gizi Anak Pra Sekolah. Care J IIm IImu Kesehat. 2017.

12. Mushtaq MU, Gull S, Khurshid U, Shad MA, Siddiqui AM. Prevalence and sociodemographic correlates of stunting and thinness among Pakistani primary school children. BMC Public Health. 2011. doi:10.1186/1471-2458-11-790

13. Kementrian Kesehatan. Infodatin, Pusat Data dan Informasi Kementrian Kesehatan RI. 2014.

14. Boucher N. Feeding Styles and the Body Weight Status of Preschool-aged Children. $J$ Nurse Pract. 2014. doi:10.1016/j.nurpra.2014.01.018

15. Soebanjono IO, Oshikoya KA, Odusanya OO NO. Prevalence of and risk factors for stunting among school children and adolescents in Abeokuta, Southwest Nigeria. Heal Popul Nutr. 2011:364.

16. Notoatmodjo S. Promosi Kesehatan dan Perilaku Kesehatan (edisi revisi 2012). Jakarta: rineka cipta. 2012. 